\title{
La investigación sobre patrones de aprendizaje en Argentina: conformación de perfiles en estudiantes de Educación Superior
}

Research on Learning Patterns in Argentina:

Profile Conformation in Higher Education

Students

Pesquisa sobre padrões de aprendizagem na Argentina: conformação de perfis em estudantes do ensino superior

María Laura de la Barrera* (iD orcid.org/0000-0002-2096-0741

Daiana Rigo** (iD orcid.org/0000-0003-0312-6429

Ana Riccetti*** iD orcid.org/0000-0002-9333-9833

doi: 10.17227/rce.num77-952

Para citar este artículo: de la Barrera, M., Rigo, D. y Riccetti, A. (2019). La investigación sobre patrones de aprendizaje en Argentina: conformación de perfiles en estudiantes de Educación Superior. Revista Colombiana de Educación, 77, 245-276. doi: 10.17227/rce.num77-9521.

\section{(c) $($ i) (8)}

* Universidad Nacional de Río Cuarto, Argentina. Correo electrónico: mbarrera@hum.unrc.edu.ar

** Universidad Nacional de Río Cuarto, Argentina. Consejo Nacional de Investigaciones Científicas y Técnicas (Conicet). 


\section{Resumen}

Nos propusimos realizar una revisión de investigaciones en relación con la aplicación del Inventory of Learning Styles de Jan Vermunt, en estudiantes de nivel superior en Argentina. En primer lugar, presentamos una consideración de diversos artículos que han resultado de una búsqueda de publicaciones académicas llevadas a cabo en Argentina entre los años 2009 y 2016. En segundo lugar, realizamos un estudio de campo a partir de datos propios recolectados desde 2006, lo que nos permitió redefinir dichos perfiles. En este sentido, llevamos a cabo análisis estadísticos de datos multivariada denominada clúster jerárquico, que dan lugar a recrear determinados perfiles propios del "sur del sur". Finalmente, examinamos los hallazgos de los doce artículos seleccionados por estudiar los patrones de aprendizaje en estudiantes de nivel superior en Argentina, con sus correspondientes análisis y resultados.

\section{Palabras clave}

Patrones de aprendizaje: estudiantes; nivel superior; perfiles; Argentina

\section{Keywords}

Learning patterns; students; higher education; profiles; Argentina

\begin{abstract}
The purpose of this study was to carry out a research review concerning the application of Jan Vermunt's ILs questionnaire (Inventory of Learning Styles) in higher education and university students in Argentina. First, we present a consideration of several articles that have resulted from a search of academic publications carried out in Argentina between 2009 and 2016. Then, we perform a field study based on our data-collected since 2006-, which allowed us to redefine those profiles. In this sense, we carry out statistical analyses of multivariate data called hierarchical cluster, which result in recreating certain profiles typical of the "South of the South". Finally, we examine the findings of the twelve articles selected for studying the learning patterns of higher level students in Argentina.
\end{abstract}

\section{Resumo}

Propusemo-nos a realizar uma revisão de investigações em relação à aplicação do Inventário de Estilos de Aprendizagem de Jan Vermunt, em estudantes de nível superior na Argentina. Em primeiro lugar, apresentamos uma análise de vários artigos que resultaram de uma pesquisa de publicações acadêmicas realizadas na Argentina entre 2009 e 2016. Em segundo lugar, realizamos um estudo de campo com base em nossos próprios dados coletados desde 2006, isso nos permitiu redefinir esses perfis. Neste sentido, realizamos análises estatísticas de dados multivariados denominados cluster hierárquico, que resultam na recriação de determinados perfis típicos do "Sul do Sul". Finalmente, examinamos as descobertas dos doze artigos selecionados para estudar os padrões de aprendizagem em estudantes de nível superior na Argentina, com suas correspondentes análises e resultados.

\section{Palavras-chave}

Padrões de aprendizagem; estudantes; nivel superior; perfis; Argentina 
Desde hace al menos una década en Latinoamérica se ha incorporado el modelo de patrones de aprendizaje de Vermunt (1998) para profundizar en el estudio de qué y cómo piensan los estudiantes de nivel superior en su proceso de aprendizaje. Es un modelo que ha demostrado solidez metodológica (García-Ravidá, 2017; Vermunt, Bronkhorst y Martínez-Fernández, 2014, Vermunt y Vermetten, 2004) y que se ha afianzado en educación superior.

Se han podido observar algunas particularidades en los territorios de Iberoamérica (García-Ravidá, 2017; Martínez-Fernández y Vermunt, 2015) por las que se han generado ciertas discusiones en el campo intercultural que parecen evidenciarse cuando se miran los patrones de aprendizaje más allá de la Europa centro-norte (Vermunt et al., 2014).

Podríamos suponer que ya en esa instancia donde el alumno mismo elige qué estudiar y en qué formarse no deberían existir dificultades en torno a aprender lo que se prefiere, o deberían ser menores. Sin embargo, surgen algunas que diríamos son típicas del nivel superior, incluso idiosincrásicas a los contenidos, al currículo con que se trabaja o vincula. Este puede ser el caso del manejo de determinados textos fuente en ciertas disciplinas que son de ardua lectura y el dominio de conceptos específicos.

En el estudio que dio origen a este artículo, nos propusimos realizar una revisión de investigaciones en relación con la aplicación del Inventory of Learning Styles (ILS) de Vermunt, 1998) en Argentina, en alumnos de nivel superior, para de este modo llevar a cabo análisis estadísticos particulares que nos permitan recrear determinados perfiles propios de este territorio sur del sur. Por ello, nos preguntamos: ¿Cuáles son los perfiles que se hacen marcadamente evidentes en este territorio? ¿De qué particularidades podríamos estar hablando?

En primera instancia, presentamos diversos artículos que encontramos en una búsqueda de publicaciones académicas llevadas a cabo en Argentina entre los años 2009 y 2016. Cada uno de ellos profundiza especialmente en grupos de sujetos y obtiene algunas conclusiones, que nos permitirán luego, en una segunda instancia, realizar un estudio de campo propio que nos permita redefinir dichos perfiles. Finalmente, ponemos en discusión los diversos hallazgos de dichas investigaciones con nuestros propios análisis y resultados.

\section{Diversos estudios en torno a los patrones de aprendizaje: ¿Qué hay de nuevo, viejo?}

Iniciamos con la revisión de doce artículos (tabla 1) que comprenden investigaciones publicadas desde el 2009 hasta el 2018 inclusive, llevadas a cabo en instituciones de nivel superior que reciben estudiantes de 
diversas procedencias de Argentina. Se seleccionaron por su pertinencia con respecto a los objetivos propuestos para el estudio, esto es, la redefinición de perfiles en torno a patrones de aprendizaje en estudiantes de nivel superior en Argentina. Incluso algunas investigaciones se han realizado en el marco del Grupo de Investigación, Docencia e Intervención en Patrones de Aprendizaje y Formación Investigadora en la Universidad (Pafiu), que funciona desde el 2011 en la Universidad Autónoma de Barcelona.

Cada trabajo tiene como eje de articulación el instrumento utilizado para la recolección de datos y la población objeto de estudio: se valoran los patrones de aprendizaje de estudiantes de nivel superior a partir del ILS (Vermunt, 1998), administrado de manera presencial grupal, individual, o a través del cuestionario en línea.

\section{Tabla 1.}

Artículos seleccionados para la revisión de los patrones de aprendizaje en Argentina utilizando el ILS

\begin{tabular}{|c|c|c|c|c|c|c|c|}
\hline Autores & Año & Lugar & Institución & Carreras & $\mathrm{n}$ & Sexo & $\operatorname{Edad}(\mathrm{m})$ \\
\hline $\begin{array}{l}\text { de la Barrera, } \\
\text { Elisondo y Rigo }\end{array}$ & 2014 & Río Cuarto & UNRC & $\begin{array}{l}\text { Psicopedagogía, } \\
\text { Educación Especial }\end{array}$ & 95 & $\begin{array}{l}F=89 \\
M=6\end{array}$ & 19 \\
\hline $\begin{array}{l}\text { de la Barrera, } \\
\text { Elisondo, Fagotti } \\
\text { Kucharski y Rigo } \\
\text { Elisondo et al. }\end{array}$ & $\begin{array}{l}2014 \\
2015\end{array}$ & Río Cuarto & $\begin{array}{c}\text { UNRC e } \\
\text { Institutos } \\
\text { Superiores } \\
\text { de Formación } \\
\text { Docente ISMI } \\
\text { e ISRMP }\end{array}$ & $\begin{array}{l}\text { Profesorados: } \\
\text { Educación Física, } \\
\text { Educación Inicial, } \\
\text { Educación Primaria, } \\
\text { Psicología, Historia }\end{array}$ & 187 & $\begin{array}{l}F=121 \\
M=66\end{array}$ & 20 \\
\hline de la Barrera & 2013 & Río Cuarto & UNRC & $\begin{array}{c}\text { Facultades: } \\
\text { Agronomía } \\
\text { y Veterinaria, } \\
\text { Ciencias } \\
\text { Económicas, } \\
\text { Ciencias Exactas, } \\
\text { Ciencias Humanas, } \\
\text { Ingeniería }\end{array}$ & 538 & $\begin{array}{l}F=292 \\
M=246\end{array}$ & 19 \\
\hline $\begin{array}{l}\text { de la Barrera, } \\
\text { Donolo y } \\
\text { Rinaudo }\end{array}$ & 2010 & Río Cuarto & UNRC & $\begin{array}{c}\text { Facultades: } \\
\text { Agronomía } \\
\text { y Veterinaria, } \\
\text { Ciencias } \\
\text { Económicas, } \\
\text { Ciencias Exactas, } \\
\text { Ciencias Humanas, } \\
\text { Ingeniería }\end{array}$ & 516 & $\begin{array}{l}F=292 \\
M=224\end{array}$ & 19 \\
\hline de la Barrera & 2010 & Río Cuarto & UNRC & $\begin{array}{c}\text { Facultades: } \\
\text { Agronomía } \\
\text { y Veterinaria, } \\
\text { Ciencias } \\
\text { Económicas, } \\
\text { Ciencias Exactas, } \\
\text { Ciencias Humanas, } \\
\text { Ingeniería }\end{array}$ & 538 & $\begin{array}{l}F=292 \\
M=246\end{array}$ & 19 \\
\hline $\begin{array}{l}\text { de la Barrera, } \\
\text { Travaglia, Sigal } \\
\text { y Fenoglio }\end{array}$ & 2014 & Río Cuarto & UNRC & $\begin{array}{l}\text { Psicopedagogía, } \\
\text { Educación Especial }\end{array}$ & 58 & $\begin{array}{l}F=56 \\
M=2\end{array}$ & 20 \\
\hline
\end{tabular}




\begin{tabular}{|c|c|c|c|c|c|c|c|}
\hline Autores & Año & Lugar & Institución & Carreras & $\mathbf{n}$ & Sexo & Edad (m) \\
\hline Elisondo et al. & 2016 & Río Cuarto & $\begin{array}{l}\text { UNRC } \\
\text { ISMI }\end{array}$ & $\begin{array}{l}\text { Profesorado de } \\
\text { Educación Inicial }\end{array}$ & 62 & $F=62$ & $\begin{array}{l}\text { UnRC (18- } \\
23 \text { años) } \\
\text { ISMI (18- } \\
30 \text { años }\end{array}$ \\
\hline $\begin{array}{l}\text { de la Barrera } \\
\text { y Riccetti }\end{array}$ & $\begin{array}{c}\text { En } \\
\text { proceso } \\
\text { de } \\
\text { edición }\end{array}$ & Río Cuarto & UNRC & $\begin{array}{l}\text { Profesorado en } \\
\text { Educación Física }\end{array}$ & 190 & $\begin{array}{l}F=93 \\
M=97\end{array}$ & 20 \\
\hline Vázquez & 2009 & $\begin{array}{l}\text { Buenos } \\
\text { Aires }\end{array}$ & UPBA & $\begin{array}{l}\text { Programa de } \\
\text { tutorías en } \\
\text { ingeniería }\end{array}$ & 420 & $\begin{array}{l}\text { No se } \\
\text { registró } \\
\text { el dato }\end{array}$ & 20 \\
\hline $\begin{array}{l}\text { Rodríguez } \\
\text { Nouche, Bouza, } \\
\text { Alves de Lima }\end{array}$ & 2016 & $\begin{array}{l}\text { Buenos } \\
\text { Aires }\end{array}$ & $\begin{array}{c}\text { Servicio de } \\
\text { Internación } \\
\text { Clínica Médica } \\
\text { Sanatorio de } \\
\text { los Arcos, } \\
\text { Departamento } \\
\text { de Educación } \\
\text { Instituto } \\
\text { Cardiovascular } \\
\text { SwissMedical. } \\
\text { com.ar }\end{array}$ & $\begin{array}{c}\text { Medicina Interna } \\
\text { (posgrado) }\end{array}$ & 14 & $\begin{array}{l}\text { No se } \\
\text { registró } \\
\text { el dato }\end{array}$ & $\begin{array}{l}\text { No se } \\
\text { registró } \\
\text { el dato }\end{array}$ \\
\hline $\begin{array}{l}\text { González y } \\
\text { Difabio de Anglat }\end{array}$ & 2016 & Mendoza & UnCUYO & $\begin{array}{c}\text { Facultad de } \\
\text { Ingeniería, } \\
\text { Facultad de } \\
\text { Ciencias Agrarias }\end{array}$ & $\begin{array}{c}239^{\circ} \\
110\end{array}$ & $\begin{array}{l}F=42 \\
M=196 \\
F=70 \\
M=40\end{array}$ & $\begin{array}{l}\text { Mín. }=17 \\
\text { Máx. }=42\end{array}$ \\
\hline
\end{tabular}

a Estudio transversal: 239; estudio longitudinal: 110

Fuente: elaboración propia a partir de los datos obtenidos en la revisión bibliográfica

El ILS consiste en 120 afirmaciones acerca de actividades, estrategias y motivos para estudiar que se distribuyen en cuatro dominios. Vermunt (1998, 2005) postula que la combinación entre los cuatro dominios definirá cada patrón de aprendizaje: 1) concepciones de aprendizaje, que tienen que ver con el desarrollo de un sistema coherente de creencias acerca de cómo se concibe el conocimiento; 2) estrategias de procesamiento, que aluden a diferentes actividades de estudio para procesar los contenidos de aprendizaje, por ejemplo, relacionar conceptos, seleccionar información, utilizar ejemplos y aplicarlos en la práctica; 3) estrategias de regulación, vinculadas con las actividades de aprendizaje, que implican cierta dinámica de toma de conciencia y control, o no, por parte de la persona que aprende; y 4) orientaciones de aprendizaje, centradas en un dominio completo de metas, intenciones, actitudes, preocupaciones y dudas de los alumnos en relación con sus estudios.

Respecto de las opciones de respuesta, la escala ofrece alternativas en formato Likert que van de "Lo hago rara vez o nunca" a "Lo hago siempre" (1 y 5, respectivamente), para los ítems sobre estrategias; y de "Totalmente en desacuerdo" a "Completamente de acuerdo" (1 y 5, respectivamente), para los ítems referidos a los motivos para estudiar y perspectivas sobre el estudio. 
Los resultados que se obtienen con esta escala se interpretan desde un punto de vista teórico a partir de combinaciones específicas. Concretamente se identifica una estructura de cuatro patrones de aprendizaje, a saber: dirigido al significado (MD), dirigido a la aplicación ( $A D)$, dirigido a la reproducción (RD) y no dirigido (UD).

\section{Mapeo de estudios sobre patrones de aprendizaje en Argentina}

Abordamos en primer lugar el artículo escrito por de la Barrera, Elisondo y Rigo (2014) "Alfabetización académica y emocional. Aproximaciones a partir de alumnos ingresantes de la Universidad"; luego, el de de la Barrera et al. (2014) "Patrones de aprendizaje y formación de formadores. ¿Cómo aprenden los que van a enseñar?"; y finalmente el de Elisondo et al. (2015), "Cómo leen, escriben y aprenden los estudiantes de educación superior. Innovación y mixtura en una experiencia de investigación".

Estos artículos toman como muestra estudiantes del nivel superior de Argentina. Mientras que el primer trabajo contempla una muestra de carreras afines al campo de la educación de la Universidad Nacional de Río Cuarto (UNRC), Provincia de Córdoba, los dos estudios restantes toman estudiantes de diversos profesorados de las ciencias sociales, no solo de dicha casa de estudios, sino además de dos institutos de formación docente de la ciudad de Río Cuarto: el Instituto Superior María Inmaculada (ISMI) y el Instituto Superior Ramón Menéndez Pidal (ISRMP). En todos los casos se trabajó con un muestreo por conveniencia (Casal y Mateu, 2003).

El primer estudio tiene su origen en una convocatoria que realiza la UNRC conjuntamente con la Facultad de Ciencias Humanas, orientada a formular e implementar el programa de ingreso, permanencia y egreso de estudiantes, ${ }^{1}$ con el objetivo principal de promover la alfabetización académica y emocional así como la implementación de diversas estrategias para tal finalidad, a través de la puesta en acción de talleres teórico-prácticos para trabajarlos entre alumnos y docentes de nivel superior (tabla 1).

Entre los resultados principales, se destacan aquellos aspectos diferenciadores encontrados respecto de los patrones de aprendizaje y en relación con la edad, la procedencia y el rendimiento académico. Considerando las edades, los estudiantes más jóvenes o ingresantes (17 y 19 años vs. 20 a 23 años) mostraron una tendencia a regular los procesos y resultados de aprendizaje con soportes externos; igualmente, este mismo grupo etario se

1 Proyecto Encuentros para la Integración Universitaria (años 2013/2014). En este marco, las autoras presentan una propuesta general, titulada "Contextos instructivos y de aprendizaje en la universidad. Patrones de aprendizaje, metacognición, creatividad e inteligencia emocional como aspectos condicionantes de rendimiento académico en alumnos ingresantes". 
sentía más proclive a las autoevaluaciones en relación con querer probarse a sí mismos que eran capaces de realizar estudios superiores, demostrarles a los demás que tenían capacidad para llevar a cabo con éxito estudios superiores. Con respecto a la procedencia, los estudiantes residentes en el lugar donde se encuentra la institución en la que estudian, tendían a exponer una orientación ambivalente, esto es, a manifestar dudas en torno a que el área elegida fuera la adecuada y tener poca confianza en su capacidad de estudio. En cambio, los que no residían, que provenían de unos kilómetros más lejos, mostraron un uso más frecuente de las estrategias que tienen que ver con relacionar y estructurar, tales como integrar en un todo los temas que son tratados en un curso en forma separada y con estrategias de análisis.

Finalmente, sobre la variable rendimiento académico, se tomaron tres medidas: la nota obtenida en un examen parcial de la asignatura Pedagogía, la de un trabajo práctico de la misma materia, consistente en escribir un informe, y la de un trabajo práctico en el que debían escribir un resumen en la materia Estrategias para el Trabajo Intelectual, ambas materias anuales de primer año. Los resultados mostraron dos agrupaciones en general: estudiantes con puntuaciones entre 5 y 7,5 y alumnos con puntuaciones desde 7,6 hasta 9. El último grupo consideraba el aprendizaje en términos de interés personal, usaba estrategias de procesamiento concreto; esto es, la posibilidad de utilizar lo aprendido en un curso en sus actividades cotidianas o futura profesión (una tendencia a los patrones MD y AD). Los estudiantes de bajo rendimiento, que debieron reelaborar o no asistieron a alguna instancia de evaluación, mostraron altas puntuaciones en carencia de regulación y tenían poca confianza en su capacidad de estudio (lo que significa mayor tendencia al patrón UD). Como puede observarse, a mejores rendimientos hay una mayor tendencia a MD y AD, mientras que a rendimientos menores, se presenta una inclinación a patrones UD.

El segundo estudio muestra avances en la lectura e interpretación de los datos del primero; son los mismos datos, pero interpretados de otra manera. El tercer estudio se llevó a cabo con la misma muestra, pero se efectuaron análisis diferentes. Los describimos conjuntamente. En el artículo del 2014 se realizó una lectura general de los resultados, mientras que en el escrito del 2015 se complejizó la lectura que, por tipo de profesorado, se había iniciado en la primera fase de análisis y presentación de resultados. ${ }^{2}$ En términos generales, el proyecto se orientaba a describir los patrones de aprendizajes en estudiantes de primer año de profesorados vinculados a las ciencias sociales (tabla 1).

2 La investigación se enmarcó en el proyecto "Aprender a enseñar y enseñar a aprender: conjugando la investigación y la práctica educativa. Algunos lineamientos en pos de la permanencia y la calidad en la formación", resultado de la primera convocatoria para conformar equipos mixtos e integrados de investigación sobre problemáticas educativas

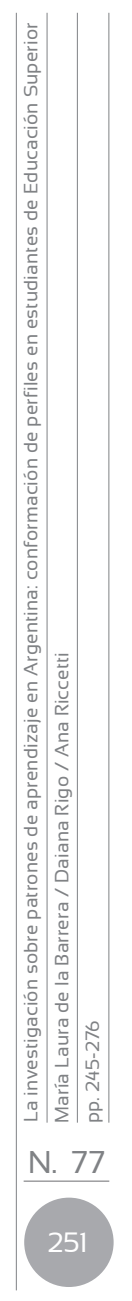


Con respecto al dominio de las estrategias de procesamiento, podemos decir que se evidenció una tendencia al uso satisfactorio de las estrategias de procesamiento profundo que tienen que ver con relacionar y estructurar (MD) y las que conciernen a un procesamiento concreto (AD). Por otra parte, muestra un uso poco satisfactorio de las estrategias referidas a pensamiento crítico, memorización y repetición y análisis. En las estrategias de regulación, los estudiantes mostraron afinidad con el uso satisfactorio de las estrategias de regulación externa de procesos de aprendizaje y de resultados de aprendizaje (RD, AD). En cuanto a la orientación del propio aprendizaje, se encontró un nivel satisfactorio en las subescalas de interés personal, motivación para obtener un título, dirigida a la autoevaluación y a la vocación. Por último, en las concepciones de aprendizaje, se evidenció un nivel satisfactorio en todas las escalas, menos en la de concebir al conocimiento como consumo, donde no se manifestó una tendencia marcada hacia extremo alguno.

A nivel específico y por carrera, con respecto a las estrategias de procesamiento, los resultados evidenciaron que los alumnos que estudiaban Educación Primaria y los de Historia hacían un mayor uso de las estrategias de procesamiento profundo (MD), referidas a analizar la información o los contenidos, en comparación con las de pensamiento crítico. Quienes cursaban Educación Inicial y los de Educación Física utilizaban estrategias de procesamiento paso a paso, como memorizar y repetir (RD). Los alumnos que cursaban Educación Primaria usaban con mayor frecuencia estrategias de procesamiento profundo, de relacionar y estructurar; así como de procesamiento concreto.

En cuanto a las estrategias de regulación, los alumnos de Educación Primaria se autorregulaban en torno al contenido de los aprendizajes y de los procesos y resultados de esos aprendizajes, mientras que los de Educación Inicial mostraban una mayor afinidad en el uso de estrategias de regulación externa de resultados de aprendizaje y dificultades para la regulación.

Respecto a las orientaciones de aprendizaje, los estudiantes de Educación Inicial y de Educación Física manifestaron una mayor tendencia a tener una motivación hacia sus aprendizajes para obtener el título, toda vez que tenían un mayor interés por la autoevaluación.

Finalmente, con relación a los modelos mentales de aprendizaje, los alumnos de Educación Inicial y los de Educación Física concebían el conocimiento en términos de consumo. Las estudiantes de Educación Inicial, en su mayoría, asociaban el conocimiento con la utilidad y, por

comunes a los institutos superiores de formación docente (región sur) y la Universidad bajo el lema "Construyendo diálogos y conocimientos: aportes para transformar las prácticas educativas". 
último, las alumnas de Educación Inicial, y los estudiantes de Educación Física mostraron mayor tendencia a concebir al docente y al educador como un estímulo.

De acuerdo con los resultados, los 187 alumnos de la muestra presentaron más de una característica correspondiente a cada patrón de aprendizaje. Ello condujo a la conclusión de que no debería dejar de reconocerse que los contenidos de cada especialidad y campo disciplinar podrían contribuir a desarrollar una u otra tendencia en el momento de definir estos patrones, que claramente distan de ser estables y fijos.

De estos dos últimos estudios descritos se derivan acciones prácticas para pensar los contextos instructivos del nivel superior. Los resultados se extrapolaron a contextos naturales de enseñanza y aprendizaje a partir de la puesta en marcha de talleres, tanto con alumnos como con docentes. De ellos se desprende que los estudiantes se mostraron preocupados por encontrar la manera de regular sus procesos y resultados de aprendizaje, de hallar un patrón particular de aprendizaje; aparentemente la búsqueda es permanente y se prolonga a lo largo de la trayectoria de formación.

Cuatro estudios más fueron: "Tareas de estudio, regulación y funciones ejecutivas en alumnos de educación superior" (de la Barrera, 2013); "Estilos de aprendizaje: particularidades en alumnos universitarios" (de la Barrera, Donolo y Rinaudo, 2010); “Competencias básicas. Aprendizaje en la universidad: particularidades de un proceso compartido" (de la Barrera, 2010); y "Patrones de aprendizaje al estudiar neurociencias: ¿Qué estrategias utilizan los alumnos?" (de la Barrera, Travaglia, Sigal y Fenoglio, 2014).

En el primero, de la Barrera (2013) hace una consideración exhaustiva del desempeño en las estrategias de regulación del ILs, aspecto que se refiere al funcionamiento ejecutivo, observando si varían en función del género, la edad, la facultad, el año en que se cursa la carrera, el nivel de rendimiento académico y el autoconcepto académico. Se trabajó con poco más de 500 estudiantes de las cinco facultades que conforman la UNRC (para más detalles, véase la tabla 1). El estudio se centra en el dominio de las estrategias de regulación; sus subescalas son: autorregulación, en relación con procesos y resultados de aprendizaje, y en relación con contenidos de aprendizaje (ejemplo: "54. Si no comprendo bien un texto al estudiar, trato de encontrar otra bibliografía sobre el tema de referencia"); regulación externa de procesos de aprendizaje y de resultados de aprendizaje (ejemplo: "32. Estudio de acuerdo con las instrucciones dadas en los materiales de estudio o provistos por el docente"); y, carencia de regulación (ejemplo: "8. Me doy cuenta de que no me queda claro qué es lo que tengo que recordar y qué es lo que no tengo que recordar"). Los resultados muestran que tanto hombres como mujeres, por edad y facultades, en su mayoría evidencian valores altos en todo tipo de regulación; lo mismo sucede por año de cursado y por rendimiento académico. Pero, 
en cuanto al autoconcepto académico, los alumnos que se consideran de desempeño regular en su mayoría muestran niveles bajos, y los que se ven como buenos, muy buenos y excelentes presentan un uso alto de las escalas de regulación. Se evidencian, en general, valores bajos para autorregulación del contenido de aprendizaje y regulación externa de procesos; valores medios en regulación externa de resultados de aprendizaje y valores bajos en carencia de regulación. Los alumnos de mayor rendimiento y nivel de autoconcepto académico están más enmarcados en patrones de aprendizaje dirigidos al significado.

En el segundo artículo, de la Barrera, Donolo y Rinaudo (2010) parten de entender el estilo cognitivo como un constructo, una estructura esencial del individuo que va a estar controlando el modo de responder a los sucesos, eventos e ideas que experimenta a lo largo de su existencia, por cuanto el estilo de aprendizaje sería un conjunto propio, característico y distintivo de inclinaciones personales para la instrucción y de actividades de aprendizaje particulares que se hallan en estrecha relación con esas característicasindividuales. Afirman que las estrategias de aprendizajerefle-jan los pasos y procedimientos que utilizan los aprendices para responder a las demandas de una tarea o actividad de aprendizaje. Mientras que las estrategias pueden variar de un momento a otro, en función de las distintas situaciones y demandas, los estilos guardarían un grado mayor de estabilidad. En su estudio con el ıs acerca de los estilos, los autores retoman a Pérez Cabaní (2000) señalando que las investigaciones de Vermunt sobre los cuatro grupos que él menciona (UD, RD, MD, $\mathrm{AD}$ ) se pueden vincular con los enfoques de aprendizaje, entendidos como "un conjunto de intenciones que orientan y condicionan las actuaciones del alumno durante el proceso de aprendizaje" (Pérez Cabaní, 2000, p. 286). La autora relaciona el estilo no dirigido con un enfoque superficial pasivo, el estilo dirigido a la reproducción con un superficialactivo, el dirigidoa la aplicacióncon un enfoque estratégicoy, finalmente, el dirigidoal significadocon un enfoqueprofundo.

Desde esta perspectiva, entre la autorregulación y el enfoque profundo se establecería una relación directamente proporcional. Por esta razón, De la Barrera et al. (2010) sostienen que lo esperable en estudiantes universitarios sería lograr una combinación de dos de los estilos que Vermunt postula: el dirigido al significado (MD) y el dirigido a la aplicación (AD). En ellos, los alumnos llegan a establecer relaciones entre los contenidos, las unidades y los diferentes temas con sus conocimientos previos, prestando también atención a aquellos que tienen relevancia práctica. De esta manera, se convierten en sujetos críticos, cuestionadores, tendientes a regularse interna y externamente, a llevar a cabo procesos metacognitivos e ir diagnosticando los porqués de sus dificultades; conciben el conocimiento como una construcción para sí mismos, no solo para aprobar materias. Se relacionan con sus docentes tomándolos como facilitadores de sus procesos de aprendizaje, 
puesto que su interés personal en los contenidos por tratar y su aplicación son los motivos fundamentales de sus estudios, interesándose siempre en las ideas de los otros y en las de formación conjunta. Los autores afirman que favorecer que los alumnos se manejen de esa manera en sus estudios universitarios implica una dosis de creatividad y compromiso muy alta tanto de los docentes como de los alumnos.

Para analizar qué estaría sucediendo en algunos casos, los autores trabajaron con poco más de 516 estudiantes de las cinco facultades que conforman la UNRC. A los alumnos se les indicó que en relación con sus calificaciones respecto al grupo clase se autoubicaran en alguna categoría: Regular, Bueno, Muy bueno y Excelentes. Los hallazgos confirmaron que de manera general quienes muestran tendencias marcadas a manejarse con patrones de aprendizaje no dirigidos son los alumnos con rendimiento académico bajo o los que se autoubicaron dentro del grupo de rendimiento bajo en relación con sus compañeros. Los alumnos de Ciencias Exactas muestran aspectos dirigidos a la reproducción, un rendimiento académico bajo y se autoubican dentro del rendimiento bajo en relación con su curso. Las mujeres se inclinan por un patrón dirigido a la aplicación y se autoubican en ese $25 \%$ de los mejores respecto a su curso. Los que evidencian tendencias a un patrón dirigido al significado son los estudiantes de rendimiento académico alto, los que se autoubican dentro del $25 \%$ de alumnos con rendimiento alto en relación con su curso y los del tramo final (cuarto y quinto año). Estos alumnos presentan más de una característica que se corresponde con cada estilo.

En el tercer artículo, de la Barrera (2010) ofrece una descripción exhaustiva del ILs; detalla inicialmente cómo considera Vermunt el estilo de aprendizaje, tomando en cuenta los componentes de aprendizaje propuestos, tales como actividades, en torno a aspectos cognitivos, afectivos y reguladores en el momento de aprender, modelos mentales y orientaciones de aprendizaje. Con base en aspectos cognitivos y metacognitivos del aprendizaje en un estudiante, se postularían entonces cuatro estilos o patrones de aprendizaje diferenciados: no dirigido, dirigido a la reproducción, dirigido al significado y dirigido a la aplicación. La autora trabajó con 516 estudiantes, con el objetivo de conocer si el desempeño en el ILS variaba en función del género, la edad, la facultad, el año que cursa en la carrera, el nivel de rendimiento académico y la autoubicación/el autoconcepto académico. Los resultados indicaron que los alumnos más avanzados en sus carreras, así como los que tienen alto rendimiento y se reconocen de esta manera son los que han evidenciado niveles de procesamiento y autorregulación en sus estrategias, más profundos y elevados en relación con el resto. Se halló además que las mujeres evidenciaron un uso satisfactorio de estrategias de cooperación, y que el grupo de alumnos con un rendimiento académico bajo o quienes se autoubican dentro del 
grupo de alumnos de bajo rendimiento no utilizaría estrategia alguna de regulación. Los alumnos con mejor rendimiento, así como aquellos que se reconocen dentro de los mejores, parecen estudiar vocacionalmente convencidos, por decirlo de alguna manera, con una relación de compromiso con el conocimiento y los contenidos que van aprendiendo, y auténticamente motivados a obtener un título profesional. La autora concluye que lo primordial y urgente en ambientes universitarios es lograr grados importantes de autonomía por parte de los alumnos, que irán alcanzándose de manera progresiva, respecto de los cuales la tarea docente continúa siendo esencial. Por ello, invita a revisar las propias prácticas, a tener un comportamiento metacognitivo, crítico, y a reflexionar sobre su toma de decisiones docentes, como modalidad esencial de intervención y calidad que redundará en la formación de profesionales de este milenio.

En un mismo sentido, en el cuarto estudio, de la Barrera, Travaglia, Sigal y Fenoglio (2014) examinaron la relación entre materias que en la carrera elegida presentan contenidos conceptuales considerados difíciles y los patrones de aprendizaje de carreras universitarias. Concretamente se propusieron conocer los patrones de aprendizaje y su relación con el desempeño de 58 estudiantes de Educación Especial y Psicopedagogía, UNRC, en el ILS, y observar si estos varían en relación con el rendimiento académico, sobre todo en las materias vinculadas a las neurociencias de tales carreras. Los resultados muestran las mayores diferencias en el segundo parcial de Neurofisiología. Se evidencia que los alumnos de promedio más bajo manifiestan mayor uso de estrategias de memorización y repetición, se encuentran más motivados a obtener un título y ven el conocimiento en términos de consumo. En este parcial los que muestran mejores promedios son los que evidencian algunos indicadores de regulación del aprendizaje y lo manifiestan también en el primer parcial de Estructuración y Patología del Lenguaje, materia que cursan posteriormente. Por último, advirtieron que los alumnos de promedio más bajo presentaron mayor evidencia de usar estrategias de relacionar y estructurar en el segundo parcial de Estructuración y Patología del lenguaje. Los patrones no son puros, surgen combinaciones que no se esperaban, lo cual les indica que debería seguirse indagando y comparando lo que sucede con materias que impliquen contenidos conceptuales diferentes.

Cuatro estudios más por considerar son: "Rendimiento académico y patrones de aprendizaje en estudiantes de ingeniería" Vázquez (2009); "Estudiantes hoy, entre Facebook, Google y Metacognición. Ideas para innovar en la Educación Superior" (Elisondo et al., 2016); "Enfoque transversal y longitudinal en el estudio de patrones de aprendizaje en alumnos universitarios de ingeniería" y "De decisiones y aprendizajes 
en la formación de profesores de educación física: poniendo en juego la metacognición" González y Difabio de Anglat (2016), y de la Barrera y Riccetti (en proceso de edición).

En el primer artículo, se exploran los patrones de aprendizaje que predominan en estudiantes universitarios de primer año que cursan carreras de ingeniería en la Universidad Tecnológica Nacional, Provincial de Buenos Aires (Argentina), en el marco de un programa de tutorías. Se plantean como objetivos específicos obtener un perfil de patrón de aprendizaje en estudiantes de ingeniería e identificar la relación que se establece entre los distintos elementos que configuran un patrón y el rendimiento académico; por último, comprobar si existen diferencias en los patrones de aprendizaje según el sexo, la edad y la escuela media de procedencia de los estudiantes. Los datos se obtuvieron durante el 2006 y el 2007 (tabla 1). También se indagó acerca de las calificaciones de exámenes parciales y finales de cuatro materias del núcleo básico de las carreras, a saber: Álgebra, Análisis Matemático, Física y Química. Además, se distingue entre estudiantes que cursan por primera vez y "crónicos" (toman los cursos, pero no presentan el examen final).

En relación con los perfiles de los estudiantes, según las actividades de procesamiento y de regulación cognitiva y los modelos mentales y orientaciones de aprendizaje, se halló que la orientación a la profesión tiene la media más alta, con diferencias significativas respecto de las demás. En cuanto a la orientación al interés personal, que permite medir la motivación intrínseca, se obtuvo una media moderada, en la cual los ítems que se destacan son: "Aprender más constituye la meta fundamental de mi estudio" y "Apunto a logros de alto nivel". El ítem que menos puntuó fue "Veo el estudio como un verdadero placer". Por consiguiente, los estudiantes buscan aprender para llegar a ser profesionales, lo que concuerda con la primacía de la concepción del conocimiento como aplicación. Los datos avalan la orientación práctica que caracteriza el perfil de la carrera.

Con relación a la acreditación, el rasgo que se destaca en el grupo es aprobar un examen como valor en sí. En el caso de los modelos mentales, predomina la concepción de conocimiento como aplicación; aunque esto resulta adecuado para el tipo de carrera, puede resultar una limitación para el perfil del futuro profesional. La media más baja corresponde a la concepción del conocimiento como cooperación, que predomina en quienes tienen rendimientos más bajos. En las estrategias de procesamiento, se destaca la de concretar, lo cual es congruente con el tipo de carrera y con la concepción del conocimiento como aplicación. Por otra parte, se obtuvieron medias bajas en el procesamiento básico y profundo, lo cual sugiere una desventaja que incide en el bajo rendimiento generalizado que caracteriza al grupo de primer año. El 80 \% de los estudiantes demuestra deficiencias en el uso de estrategias de estudio. En consecuencia, se limitan a leer, lo que constituye el 
primer momento de una rutina de estudio, que circunscribe la comprensión y fijación del conocimiento. En cuanto a las estrategias de regulación, los resultados muestran que la más utilizada es expresar un tema con palabras propias y la menos usada es planificar el modo de estudiar. Se encontró que la regulación externa tiene la media más alta.

No se hallaron relaciones entre los patrones de aprendizaje y el rendimiento académico en las cuatro asignaturas básicas estudiadas. En cambio, los análisis sí mostraron diferencias estadísticamente significativas entre los patrones de aprendizaje y la condición de estudiantes crónicos — quienes muestran un patrón más superficial de aprendizaje- y los que rinden los exámenes y los aprueban, quienes se caracterizan por el patrón de aprendizaje profundo. Se encontraron diferencias significativas según el sexo, la edad y la escuela media de procedencia en relación con los patrones de aprendizaje. En cuanto al sexo, la mayoría de las mujeres tienen un patrón profundo y superan a los varones en la motivación intrínseca. No obstante, su rendimiento académico fue más bajo.

Con respecto a la escuela media de procedencia, el grupo que proviene de una institución no técnica se caracteriza por un patrón de aprendizaje de tipo profundo. Los estudiantes de treinta años o más también presentan este patrón, con más autorregulación; esto podría sugerir que los patrones evolucionan durante el transcurso de la carrera universitaria.

En este estudio, los patrones hallados son semejantes a los encontrados por Vermunt (1998) y Vermunt y Vermetten (2004) — profundo, no orientado, aplicado y orientado a la reproducción-, con algunas diferencias en el estilo orientado a la reproducción. Se confirmaría una cierta estabilidad de estos patrones en los estudiantes de ingeniería de primer año, que resulta en una estabilidad transcultural. También se destacan indicios de evolución de los patrones debido a las diferencias encontradas a favor de estudiantes de mayor edad. Asimismo, el patrón MD permite predecir mayor probabilidad de persistencia en el estudio y en la presentación de exámenes finales, mientras que en el patrón superficial sucede lo contrario.

El perfil hallado en los estudiantes de ingeniería de primer año es congruente con la especificidad de la carrera elegida, puesto que predominan una orientación académica profesional así como la concepción del conocimiento como aplicación; esto puede resultar en una limitación debido a las demandas de profesionales con habilidades de alto nivel, creatividad y capacidad de innovación.

Por último, se observó un bajo nivel de uso de estrategias de procesamiento de la información y de autorregulación, puesto que el $80 \%$ tiene carencias en estos aspectos, lo que da lugar a un bajo rendimiento 
académico. Esto demuestra, en parte, que los estudiantes ingresan a la universidad con hábitos de estudio autorregulado insuficientes para afrontar el procesamiento comprensivo y reflexivo del conocimiento.

En el segundo artículo, de Elisondo et al. (2016), el propósito principal fue analizar aspectos metacognitivos vinculados al aprendizaje académico de estudiantes de primer año del Profesorado en Educación Inicial de la UNRC y del ISMI (Argentina). En este artículo se utilizaron dos instrumentos: un cuestionario general acerca de las prácticas y hábitos de estudio y el ILS. Aquí nos referiremos a los resultados obtenidos con el ILS (para más detalles, véase la tabla 1 ).

Los resultados, en primer lugar, se refieren al uso de estrategias de procesamiento, de memorizar y repetir. Existe un predominio de estrategias de regulación externa de resultados de aprendizaje, esto implica que las estudiantes consideran que tienen dominio del tema cuando logran completar las tareas a partir de los materiales de estudio o por la información brindada por el docente. En cuanto al autoconcepto académico, paradójicamente, las estudiantes que se valoran entre regulares y excelentes evidencian cierta carencia de regulación en el aprendizaje. En relación con las orientaciones académicas o de aprendizaje, predomina la motivación para obtener el título, de ahí la importancia otorgada a aprobar los exámenes. En este mismo sentido, conciben el conocimiento en términos de consumo de información, esto sugiere que prefieren una enseñanza en la que se les indique claramente lo que necesitan saber para un examen, de este modo emplean estrategias de memorización para dominar el tema de estudio. Por consiguiente, conciben el conocimiento como útil, en referencia a la solución de un problema práctico a partir de la aplicación de teorías. Para las estudiantes, el aprendizaje tiene que ver con la adquisición de conocimientos, la asimilación de información y habilidades que puedan poner en práctica. Por último, el docente es considerado un estímulo, alguien que las motiva y entusiasma, además de guiarlas en los contenidos en sus partes e integrarlos en un todo, alentarlas a sortear dificultades, promover la autoevaluación y reflexionar sobre aspectos metacognitivos para mejorar.

En el tercer artículo, González y Difabio de Anglat (2016) proponen analizar la modificabilidad de los patrones de aprendizaje de los estudiantes en el transcurso de la carrera universitaria y, con esto, determinar si los estudiantes manifiestan rasgos del patrón orientado al significado, en el cual se desarrolla el pensamiento crítico, flexible y adaptable a los requerimientos académicos. El diseño utilizado fue no experimental, se realizó un primer estudio transversal en el que se compararon estudiantes de primero y quinto año para identificar los patrones de aprendizaje. El segundo fue un estudio longitudinal en estudiantes de primer año, en 
el que se compararon dos instancias evaluativas en dos momentos del ciclo lectivo, para analizar el grado de variabilidad de los patrones de aprendizaje según el sexo y el rendimiento autoinformado.

En el primer estudio, el grupo estuvo conformado por 149 alumnos de primer año ( 119 hombres y 30 mujeres, de edad entre 17 y 40 años) y 89 alumnos (77 hombres y 12 mujeres, de entre 20 y 35 años) de quinto año de la Facultad de Ingeniería (Universidad Nacional de Cuyo, Mendoza, Argentina). El estudio longitudinal estuvo conformado por 110 alumnos (40 varones y 70 mujeres, con una edad entre 17 y 42 años) de primer año de la Facultad de Ciencias Agrarias (Universidad Nacional de Cuyo). La muestra fue intencional para ambos estudios (tabla 1).

A partir del análisis jerárquico de conglomerados, se hallaron cuatro grupos. En el primero se ubican las estrategias de procesamiento profundo (relación y estructuración, pensamiento crítico), análisis y pensamiento concreto, estrategias de autorregulación de procesos, resultados y contenidos del aprendizaje y orientación personal. Este primer grupo se corresponde con el patrón dirigido al significado (Vermunt, 1998). El segundo conglomerado incluye la memorización y regulación externa de procesos y de resultados, la orientación a la acreditación, a la autoevaluación y también conocimiento como incorporación; tratándose del patrón de aprendizaje dirigido a la reproducción (Vermunt, 1998, 2005). En el tercer grupo, se encontraron las restantes concepciones del aprendizaje y la orientación a la profesión, lo cual podría constituir un patrón versátil. En el cuarto conglomerado predomina la ausencia de regulación y de orientación (u orientación ambivalente), conformando un patrón no orientado. Por último, se encontraron más estudiantes de primer año orientados al patrón reproductivo/no dirigido y menos orientados al significado y al patrón versátil que en el grupo de quinto año.

En síntesis, en el estudio transversal sobre los patrones de aprendizajes identificados, se concluye que los patrones hallados no son equivalentes a los expuestos por Vermunt $(1998,2005)$. No obstante, se distingue un patrón orientado al significado y uno reproductivo. En cuanto al primero, se halló que se incrementa con el tiempo, en tanto que el segundo declina; esto demuestra que se establece una relación entre el año de cursado y el desarrollo del patrón. Por consiguiente, el patrón reproductivo predomina en el primer año de la carrera, mientras que el orientado al significado es característico del último. Se encontraron diferencias significativas durante el transcurso de la carrera universitaria en el desarrollo de los patrones a favor del profundo, lo cual resulta coherente con la evolución de la autorregulación del aprendizaje que se genera durante la carrera universitaria. 
En el segundo estudio (longitudinal), en el postest los estudiantes de primer año, en comparación con el pretest, consideran el aprendizaje menos como estímulo, se incrementan las actividades de autorregulación de procesos y de autorregulación de contenidos. También muestran menor puntuación en la orientación a la autoevaluación. El análisis jerárquico de conglomerados evidencia la conformación de cuatro grupos: patrón orientado al significado, al reproductivo, al versátil y el no orientado. Se registró un aumento de estudiantes orientados al significado, mientras que disminuyeron los orientados a la reproducción en el postest, así como en los patrones versátil y no orientado.

En cuanto al rendimiento autoinformado se encontraron relaciones significativas, puesto que quienes reportaron un nivel alto de desempeño se caracterizaron por un manejo frecuente de estrategias profundas y de autorregulación. La falta de regulación corresponde a estudiantes que expresaron un rendimiento bajo, y al mismo tiempo disminuye en aquellos de rendimiento alto. En cuanto al género, se evidencia que en ambas instancias evaluativas las mujeres presentan puntuaciones más altas respecto de los varones en conocimiento como construcción.

En el cuarto de estos estudios, realizado por de la Barrera y Riccetti (en proceso de edición), el objetivo fue conocer los patrones de aprendizaje de estudiantes de los primeros años del Profesorado de Educación Física (UNRC) y analizar los aspectos metacognitivos implicados en la elaboración de una tarea académica colaborativa y de participación activa en asignaturas de corte teórico. Aquí enfatizaremos en los patrones de aprendizaje obtenidos. El grupo de estudio lo conformaron 190 estudiantes (93 mujeres y 97 hombres; con edades entre los 18 y 29 años) que cursaban las materias Pedagogía $(n=83)$ de primer año, y Psicología Educacional y Didáctica ( $n=107)$, ambas de segundo año (tabla 1$)$.

En las respuestas, los estudiantes no evidenciaron tendencias de uso favorable en ninguna de las estrategias de procesamiento. En relación con las estrategias de regulación, el grupo muestra cierto grado de regulación autónoma, pero prevalece la externa. En el dominio de orientación del aprendizaje se encontraron tendencias satisfactorias para cada una de las escalas, lo que guarda relación con la baja puntuación obtenida en la escala ambivalente. Por último, en el dominio de modelos mentales de aprendizaje se hallaron tendencias favorables para todas las escalas, destacándose la de cooperación.

Los estudiantes de Educación Física demostraron escasa habilidad en el pensamiento crítico y concreto en el momento de procesar información; predomina la regulación externa. La orientación de sus aprendizajes se vincula al interés personal, la motivación intrínseca, la vocación y la 
intención de obtener el título. Asimismo, relacionan el aprendizaje con la construcción de conocimiento y con su utilidad; aquí también se pone de manifiesto la importancia y el valor tanto del docente como de los compañeros para realizar las tareas.

Para cerrar esta revisión, se consideró un último artículo, de Rodríguez Nouche et al. (2016) Estilos de aprendizaje y su rol en el desarrollo profesional continuo, que precisamente contempla otro nivel de formación que se relaciona con estudios de formación superior: se trata de residencias, esto es, un nivel de tipo posgradual. Por ello, se lo considera a manera de cierre.

En su investigación, los autores se proponen identificar los estilos de aprendizaje de un grupo de profesionales especialistas en Medicina Interna que realizan tareas asistenciales en un sanatorio. Utilizaron una aproximación fenomenográfica a través de una entrevista semiestructurada, fundamentada en las ventajas de este enfoque, ya que al ser exploratorio no construye sobre una teoría previamente definida acerca del tema. Este enfoque es de utilidad dado lo poco que se conoce en relación con los modelos mentales en posgraduados luego de finalizada la residencia. Los análisis fueron de corte inductivo y deductivo, puesto que, en el primero, los datos se examinan de acuerdo a puntos de interés y declaraciones significativas; respecto del segundo, se chequean aspectos identificados por la presencia de estos en los datos, continuando hasta que el investigador está seguro de que las categorías identificadas pueden estar respaldadas por los datos. Se trabajó con catorce profesionales, que en promedio tardaron seis años en concluir su residencia. Los profesionales presentaron características de los diferentes estilos identificados por Vermunt (1998), pero, a su vez, evidenciaron uno propio: uno dirigido a la incorporación de conocimientos, dos dirigidos a la construcción del conocimiento, diez a la utilización del conocimiento y uno no dirigido. Aparentemente, el modelo predominante fue el estilo referido a la utilización del conocimiento; se encontraron variantes con regulación compartida y otras más autorreguladas. Los autores se plantean que conocer los estilos de aprendizaje permitiría adaptar las estrategias educativas a las necesidades de los diferentes individuos, tanto para reforzar los estilos adecuados existentes, como para promover una práctica más autorregulada en otros y fundamentalmente tratar de estimular la mejoría de los estilos de la minoría, que pueden ser los que presenten más estrés en la capacitación, tanto por fricción por las diferencias con los instructores como por no ser tenidos en cuenta en los diseños instruccionales.

Consideran que los resultados contribuyen a comprender cómo influenciar el aprendizaje de los posgraduados, ya que la mayoría de los estudios publicados corresponden a la educación superior, grado o posgrado en etapas de entrenamiento inicial. Concluyen que el patrón 
de estilos presentes en la mayoría de los profesionales es satisfactorio y da oportunidades para facilitar la enseñanza clínica así como una práctica reflexiva.

\section{Patrones de aprendizaje: algunos hallazgos particulares en la elaboración de perfiles en estudiantes de nivel superior}

A continuación se detalla el análisis de datos desarrollado para dar respuesta a nuestros interrogantes: ¿Cuáles son los perfiles que se hacen marcadamente evidentes en este territorio? ¿De qué particularidades podríamos estar hablando? Su objetivo es reconocer y describir patrones de aprendizaje propios de estudiantes de nivel superior, de lo que denominamos región sur del Sur, Argentina.

Se trata de una investigación descriptiva de corte cuantitativo, que retoma datos recolectados en estudios previos para profundizar sobre los perfiles de patrones de aprendizaje a través de la aplicación del ıs.

\section{Escenarios de investigación}

Para la presente investigación reunimos una muestra de 1069 estudiantes de educación superior, pertenecientes a tres instituciones ubicadas al sur de la Provincia de Córdoba, del departamento de Río Cuarto, Argentina, a saber: Universidad Nacional de Río Cuarto $(\mathrm{n}=1,035)$, Instituto Superior María Inmaculada $(n=11)$ e Instituto Superior Menéndez Pidal $(n=23)^{3}$. La edad promedio del grupo fue de 20 de años $(S d=2,7)$ y la mayoría fueron mujeres $(66 \%)$. Con respecto a la distribución por año cursado, un $37 \%$ se encontraba en el primer año de la carrera, un $32 \%$ en segundo, un $19 \%$ en tercero, un $8 \%$ en cuarto, el resto en quinto y sexto años, finalizando el cursado.

Los datos forman parte de estudios previos desarrollados en el marco de diversos proyectos de investigación (Prodec, Promiie, Piimeg), desde 2009 hasta 2018. Todos los participantes dieron su consentimiento informado para participar en los estudios.

\section{Instrumentos}

Se utilizaron dos instrumentos utilizados: la versión en español del ILS (Vermunt, 1998) adaptada por Martínez Fernández et al. (2009) y un cuestionario sociodemográfico.

3 Consideramos solo los datos obtenidos en los proyectos en que participamos, por eso no se incluyen los estudiantes de uncuyo y de posgrado. 
En el ILS se contempla una escala en formato Likert que va de (1) "Lo hago rara vez o nunca" a (5) "Lo hago siempre", para los ítems sobre estrategias; y de (1) "Totalmente en desacuerdo" a (5) "Completamente de acuerdo" para dar respuesta a los diversos ítems referidos a motivos para estudiar y perspectivas respecto al aprender. En síntesis, el instrumento permite indagar sobre cuatro dominios, que se presentan y describen en la tabla 2.

\section{Tabla 2.}

Dominios, escalas y subescalas del ILS

\begin{tabular}{|c|c|}
\hline Dominios/Estrategias & Escalas y subescalas \\
\hline Procesamiento cognitivo & $\begin{array}{l}\text { Procesamiento profundo } \\
\text { - Relación y estructuración } \\
\text { - Pensamiento crítico } \\
\text { Procesamiento paso a paso: } \\
\text { - Memorización y repaso } \\
\text { - Análisis } \\
\text { Procesamiento concreto }\end{array}$ \\
\hline Regulación del aprendizaje & $\begin{array}{l}\text { Autorregulación } \\
\text { - de los procesos y resultados de aprendizaje } \\
\text { - de los contenidos de aprendizaje } \\
\text { Regulación externa } \\
\text { - de los procesos de aprendizaje } \\
\text { - de los resultados de aprendizaje } \\
\text { Ausencia de regulación }\end{array}$ \\
\hline Orientaciones del aprendizaje & $\begin{array}{l}\text { Interés personal } \\
\text { Dirigida a obtener un título } \\
\text { Dirigida a la autoevaluación } \\
\text { Dirigida a la vocación } \\
\text { Ambivalente }\end{array}$ \\
\hline Modelos mentales de aprendizaje & $\begin{array}{l}\text { Construcción del conocimiento } \\
\text { Consumo del conocimiento } \\
\text { Uso del conocimiento } \\
\text { Docente como estímulo } \\
\text { Cooperación }\end{array}$ \\
\hline
\end{tabular}

a Traducción propia.

En cada estudio se aplicó el cuestionario sociodemográfico ad hoc para solicitar datos personales de los estudiantes (como edad y género), así como de índole académica, referidos a la institución donde estudian y el año cursado. Se consideró además la autoubicación del estudiante en función de su rendimiento académico mediante la elección de una de las siguientes opciones: No sabe/No contesta, Malo, Regular, Bueno, Muy bueno y Excelente. 


\section{Análisis de datos}

Para el análisis se utilizó la técnica de análisis de datos multivariada denominada clúster jerárquico, que tiene como propósito principal identificar grupos que sean homogéneos en su interior y que mantengan diferencias entre ellos. Para el procesamiento de los datos se utilizó el programa estadístico sPSs versión 16.

En un primer momento, se estandarizaron las variables con el objetivo de unificar sus escalas. El agrupamiento se decidió por caso y se usó el método de Ward, para minimizar la varianza intragrupal y maximizar la homogeneidad dentro de los grupos; previamente se chequeó la presencia de datos extremos. Se tomó como punto de corte la distancia 12 para identificar los grupos, sabiendo que a menor distancia los conglomerados son más parecidos.

En un segundo momento, a partir de un análisis univariado se describieron los grupos identificados, con el objetivo de caracterizarlos en función de las variables en estudio; finalmente, las consideradas fueron: por un lado, género, año de cursado e institución de pertenencia, por otro lado, autoubicación de pertenencia como alumnos y los cuatro dominios, a saber: estrategias de procesamiento, estrategias de regulación, orientación de aprendizaje y modelos mentales de aprendizaje y sus respectivas subescalas.

\section{Resultados}

Como se aprecia en la figura 1, se identifica la conformación de dos clústers a la distancia 12. En el primero, se concentra el $55 \%$ de la muestra (G1) y en el segundo el $45 \%$ (G2). Las agrupaciones muestran particularidades que describen a los integrantes en función de las variables estudiadas, sobre todo en lo referido a los patrones de aprendizaje descritos por Vermunt, que analizaremos a continuación. 


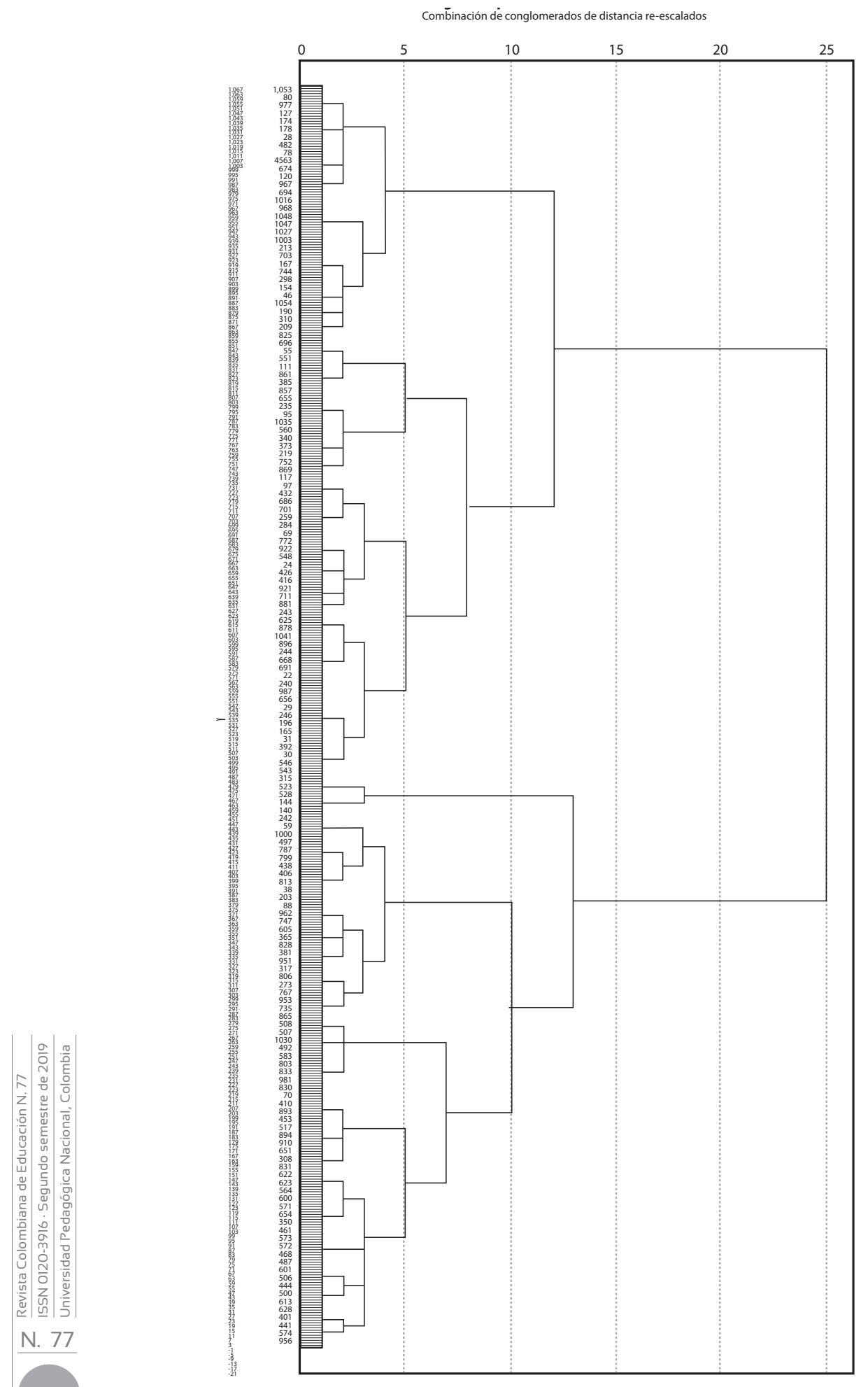

Figura 1. Dendrograma

Fuente: elaboración propia. 
En los grupos (G1 y G2) no aparecen como rasgos que delimiten diferencia entre ellos el sexo, la institución de pertenencia, el año de curso, la edad y la autoubicación escogida respecto al sentido de pertenencia desarrollado como alumno. En cambio, sí se observan tendencias dispares dentro de las dimensiones que definen a cada dominio.

Con respecto a estrategias de procesamiento del dominio I (figura 2), encontramos que la mayoría de los estudiantes del grupo G1 puntúa alto en relacionar y estructurar, en memorización y repetición, en análisis, procesamiento concreto y pensamiento crítico. Sobre esta última dimensión el G2 también muestra fortaleza: la mayoría de los estudiantes se reconocen con dicha habilidad como elevada. No obstante, en el resto de las dimensiones del dominio I, este grupo puntúa bajo, de modo que parece el más auténticamente MD.

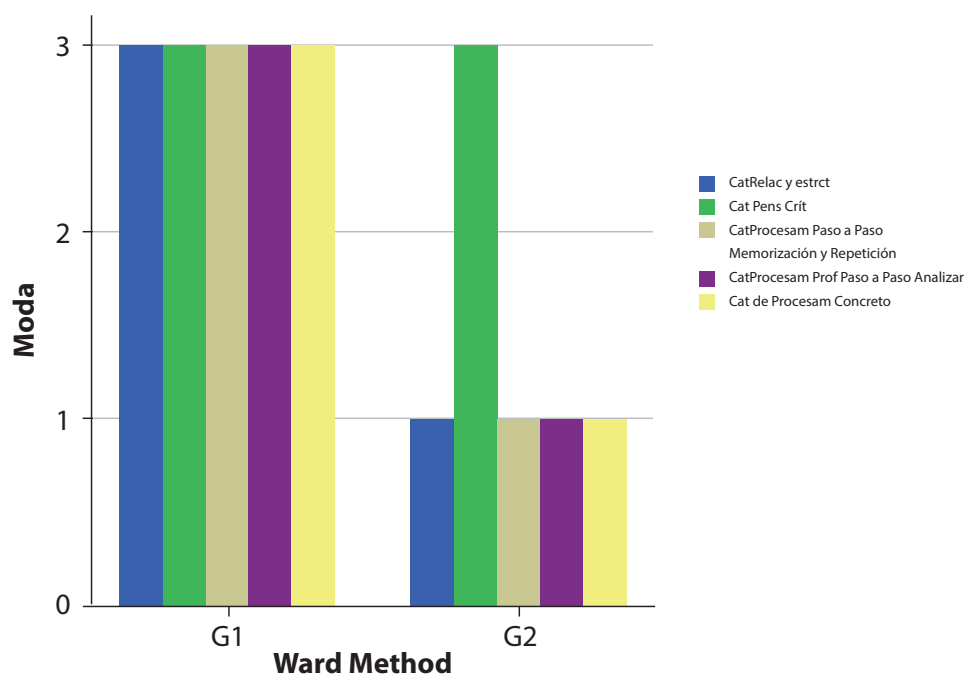

Figura 2. Dominio ı. Estrategias de procesamiento

Fuente: elaboración propia.

Con relación al dominio denominado estrategias de regulación (figura 3), encontramos nuevamente que el G1 muestra la activación de todo tipo de estrategias de regulación (internas y externas) en torno a los procesos de autorregulación, tanto de procesos y resultados como de contenido de aprendizaje. Asimismo, el grupo muestra una tendencia a requerir de apoyos externos para la regulación de los procesos y resultados de aprendizaje junto a la apreciación de una elevada carencia en regulación, por cuanto 
la mayoría de los estudiantes obtiene puntuaciones altas. Por el contrario, el G2 muestra debilidades en cada dimensión del dominio ॥, apreciadas en puntuaciones bajas en la mayoría de los alumnos que lo integran.

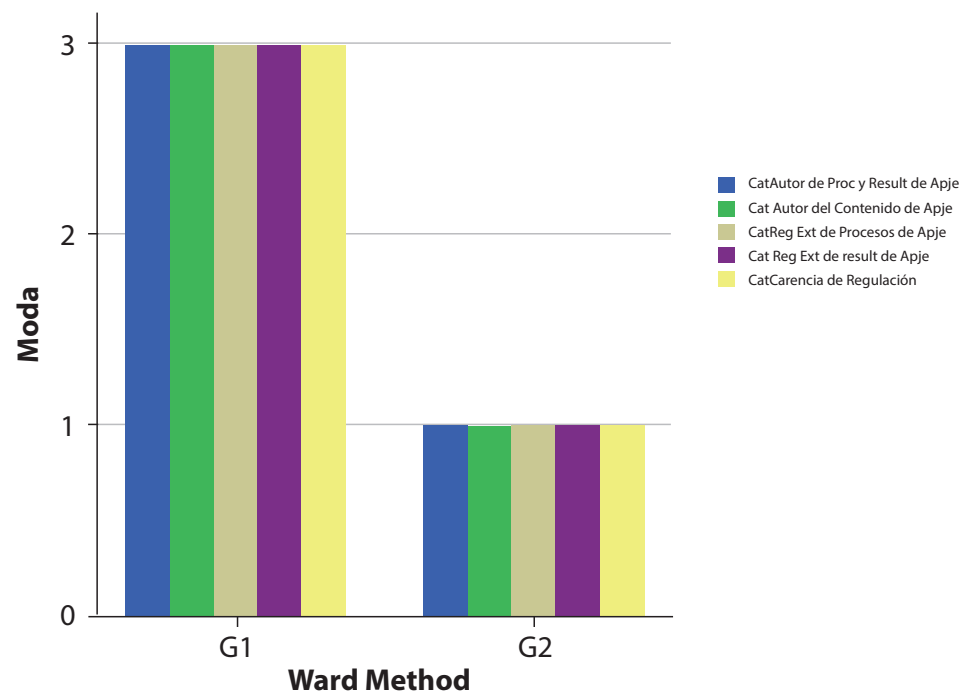

Figura 3. Dominio II. Estrategias de regulación

Fuente: elaboración propia.

En cuanto al dominio III, Orientación del aprendizaje (figura 4), se observa en el G1 gran interés personal, motivación para obtener certificaciones, acciones orientadas a la autoevaluación, a tomar decisiones basadas en sus elecciones vocacionales y tendencia a la ambivalencia; en cada dimensión la mayoría de los estudiantes muestra puntuaciones altas. Con respecto al G2, se observan debilidades en tres de las dimensiones nombradas, menos en interés personal y vocación, en las que la mayoría de los alumnos obtiene una puntuación media. 


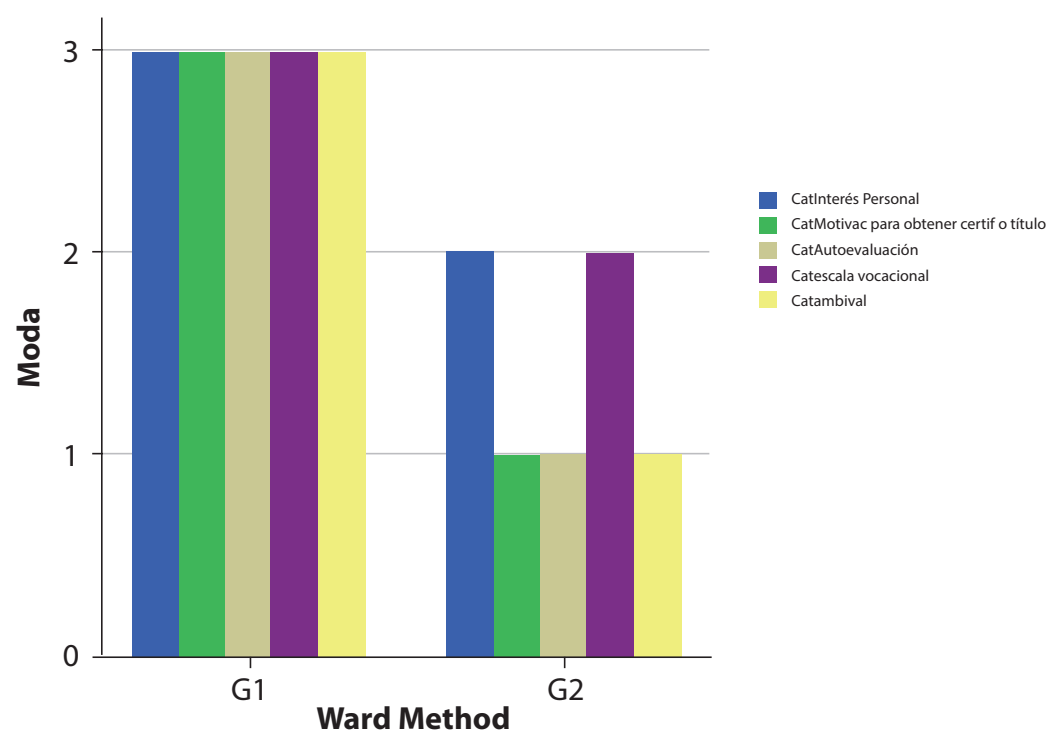

Figura 4. Dominio III. Orientación del aprendizaje.

Fuente: elaboración propia.

Por último, en el dominio Iv, modelos mentales de aprendizaje (figura 5), encontramos que el G1 presenta puntuaciones altas en todas las categorías, mientras que en el G2 la mayoría vuelve a presentar puntuaciones bajas en cada dimensión de los modelos mentales de aprendizaje, a excepción de la escala Concebir al educador como estímulo (UD), donde obtienen puntuaciones medias. 


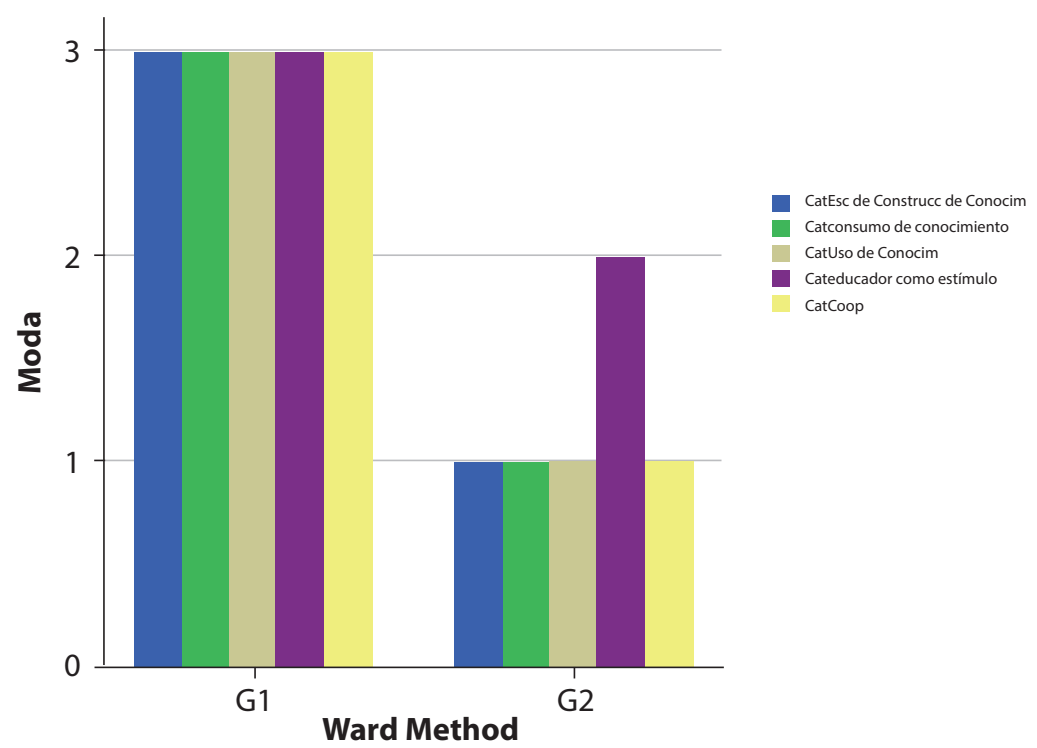

Figura 5. Dominio Iv. Modelos mentales de aprendizaje

Fuente: elaboración propia

En síntesis, se pone en evidencia que en la muestra estudiada se observan claramente dos patrones de aprendizaje que caracterizan a los estudiantes de nivel superior respecto a los comportamientos, acciones y procesos que ponen en marcha cuando estudian. Uno que podríamos denominar de monitoreo continuo o sostenido y otro que llamaremos libre de control de procedimientos. Estas etiquetas surgen de la caracterización de uno y otro perfil, producto del análisis minucioso de los procedimientos, actitudes y convicciones que implican. La tabla 3 sintetiza las características propias de uno y otro patrón. 
Tabla 3.

Patrones emergentes de los estudiantes de nivel superior Sur del Sur en consonancia con el $\mathrm{LS}^{a}$

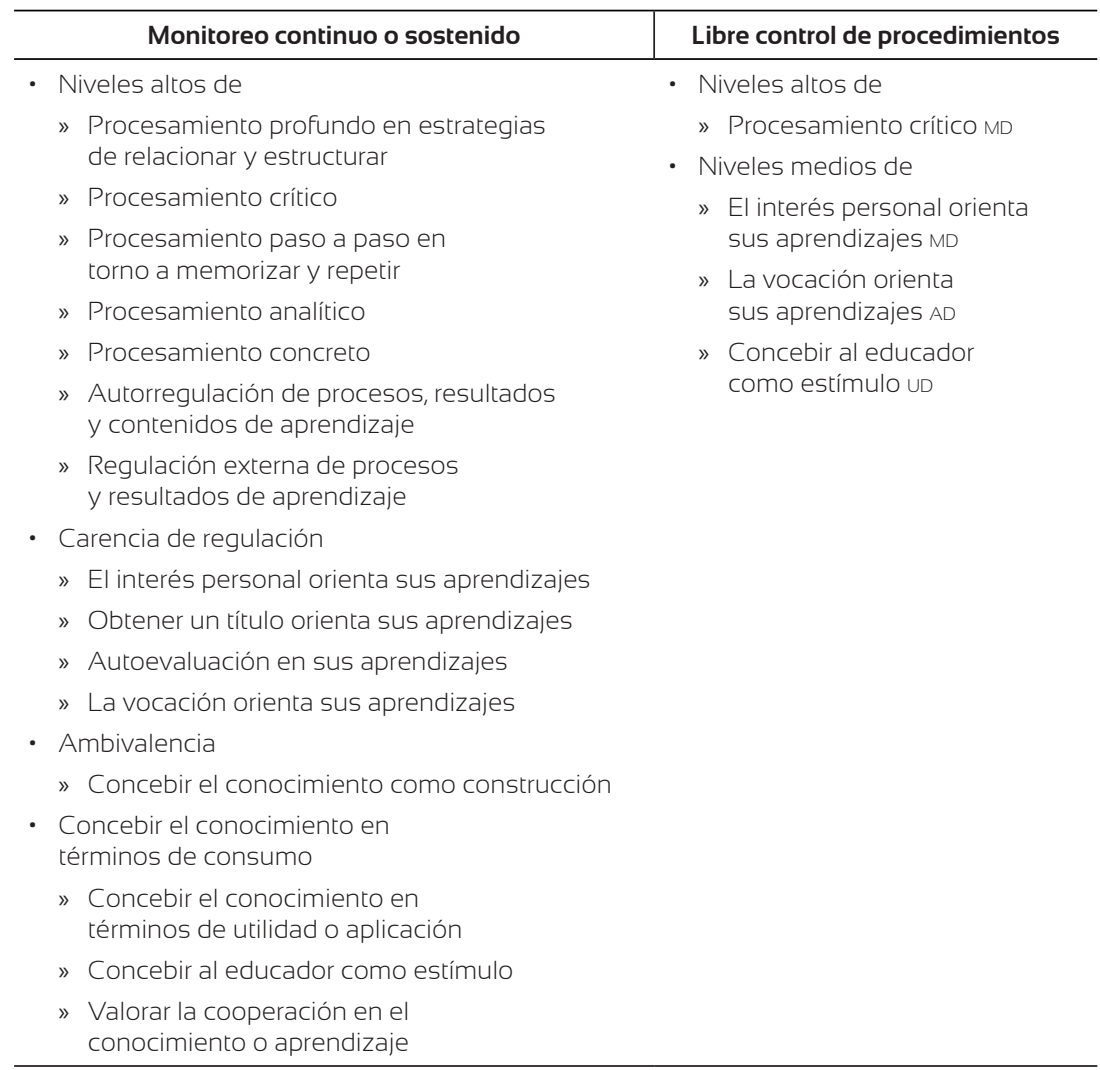

Fuente: elaboración propia

Claramente es el criterio de algún tipo de control el que marca la diferencia entre uno y otro. El primero evidencia conductas de vigilancia o alerta permanente en los procesos de aprendizaje, incluyendo recursos humanos, contenidos y tipos de regulación Se destaca un comportamiento metacognitivo continuo, lo que quizás da cuenta de que todo vale, todo se controla o piensa, incluso cuando aparecen dudas (carencia de regulación, ambivalencia y concebir el conocimiento en términos de consumo).

El segundo patrón manifiesta una carencia de revisión o regulación sostenida. Las eventualidades se van resolviendo a medida que suceden sin planificación alguna, esto podría explicar sus altos niveles de procesamiento crítico y niveles medios respecto del interés personal y la vocación. 


\section{Algunas consideraciones finales}

Tras la revisión de los diferentes artículos en torno al tema que nos convoca en este monográfico, podemos hacer algunas aseveraciones interesantes que se evidenciaron en mayor o menor medida en nuestros propios análisis con la muestra conformada.

Se deducen varias cuestiones, como, por ejemplo, que los profesores se preguntan cómo pueden acompañar a los estudiantes en su búsqueda o ayudarlos para que persistan, sobre todo a quienes hacen el esfuerzo para sostener sus estudios a pesar de las dificultades. Docentes y alumnos coinciden en que es esencial el acompañamiento tanto de profesores como de los mismos estudiantes, y en que es necesario que a través de la formación teórica se pongan en ejecución procesamientos concretos, que permitan utilizar lo aprendido en sus actividades cotidianas y futuro desempeño profesional. En este aspecto, la tarea esencial sigue recayendo en el docente, y el alumno debería esforzarse para que esto suceda.

Los resultados sugieren que en ambientes universitarios debe tenderse a desarrollar en los alumnos grados importantes de autonomía, que ha de alcanzarse de manera progresiva y en la cual la tarea docente continúa siendo esencial. Con ello, es imperativo repensar las propias prácticas, tener un comportamiento metacognitivo, crítico, y reflexionar sobre la propia toma de decisiones docentes para contribuir a la formación de profesionales de calidad. Se destaca la idea de favorecer estrategias de procesamiento profundo, autónomo, crítico y reflexivo, que permitan la construcción del conocimiento a partir de andamios didácticos generados en el entorno educativo. Por lo tanto, se deja ver que las variables personales y contextuales han de combinarse de la mejor manera para generar ámbitos y ambientes académicos de calidad.

Surge también la idea de que a medida que transcurren sus estudios los estudiantes van desarrollando más estrategias de autorregulación en el aprendizaje. Los patrones de aprendizajes identificados en la mayoría de los estudios son: dirigido al significado y dirigido a la reproducción; esto coincide, por ejemplo, con Martínez Fernández y García Ravidá (2012) y Martínez Fernández (2015).

En nuestro estudio se suman otras características, no tan diferentes, pero con ciertas particularidades. Se identifican dos tipos de alumnos: el primero manifiesta un seguimiento continuo de los procesos de aprendizaje, toma de decisión y la construcción de significados ya sea de manera interna o externa, utilizando cualquier procedimiento que sirva para tal efecto, concibiendo el conocimiento en términos de construcción y de utilidad, y al educador y a los compañeros como parte importante de su propio proceso de aprendizaje. En cambio, el otro grupo no responde a ningún tipo de control, se comporta en función de cómo van ocurriendo 
las diversas situaciones, sin monitoreo alguno, aunque centrados en lo que van aprendiendo; valoran la intervención del profesor y destacan la propia motivación porque da un sentido a lo aprendido basándose en propuestas del docente.

Algunos resultados nos han sorprendido, pero, en otros, responden a lo que se espera acerca del cómo deberían hacer los estudiantes de nivel superior. Quien transita estos niveles de educación está convencido de lo que quiere hacer en su futuro; por lo tanto, paulatinamente irá configurando su propio patrón. Las ansias de aprender, los qué, los cómo y los cuándo irán definiéndose en la trayectoria académica. En este sentido, se hace esencial la configuración de un pensamiento metacognitivo permanente en estos niveles. En ese camino, aparentemente de desarrollos individuales, la relación con otros sigue siendo lo que contribuirá a conformar una subjetividad profesional suigéneris. Apostemos a la educación, con y para otros, siempre.

\section{Referencias}

Casal, J. y Mateu, E. (2003). Tipos de muestreo. Rev. Epidem. Med. Prev, 1, 3-7. de la Barrera, M. L. (2010). Tareas de estudio, regulación y funciones ejecutivas en alumnos universitarios. Ponencia presentada durante el $v$ Congreso Marplatense de Psicología, organizado por la Universidad Nacional de Mar del Plata, Argentina.

de la Barrera, M. L. (2013). Tareas de estudio, regulación y funciones ejecutivas en alumnos de educación superior. Revista Argentina de Ciencias del Comportamiento, Suplemento (julio). Recuperado de www.psyche.unc.edu.ar/racc.

de la Barrera, M. L., Donolo, D. y Rinaudo, M. C. (2010) Estilos de aprendizaje: particularidades en alumnos universitarios. Revista Estilos de Aprendizaje, 6(6), 1-27. http://www.uned.es/revistaestilosdeaprendizaje.

de la Barrera, M. L., Elisondo, R., Fagotti Kucharski, E. y Rigo, D. (2014). Patrones de aprendizaje y formación de formadores. ¿Cómo aprenden los que van a enseñar? En Abraham, M. de los A. et al (coords.). v Congreso Marplatense de Psicología: "La Psicología como promotora de derechos, hacia la interdisciplinariedad de las prácticas en los escenarios actuales" (pp. 1182-1187). Mar del Plata: Universidad Nacional de Mar del Plata. Recuperado de http://www.seadpsi.com. ar/eventos/actas/actas.pdf.

de la Barrera, M. L., Elisondo, R. y Rigo, D. (2014). Alfabetización académica y emocional. Aproximaciones a partir de alumnos ingresantes de la universidad. Contextos de Educación, 14(16). Recuperado de www.hum.unrc.edu.ar/publicaciones/contextos. 
de la Barrera, M. L., Travaglia, P., Sigal, D. y Fenoglio, S. (2014). Patrones de aprendizaje al estudiar neurociencias: ¿Qué estrategias utilizan los alumnos? En Abraham, M. de los A. et al (coord.). vı Congreso Marplatense de Psicología: "La Psicología como promotora de derechos, hacia la interdisciplinariedad de las prácticas en los escenarios actuales" (pp. 492-496). E-book Mar del Plata: Universidad Nacional de Mar del Plata. Recuperado de http://www.seadpsi.com.ar/ eventos/actas/actas.pdf.

de la Barrera, M. L. y Riccetti, A. (en proceso de edición). De decisiones y aprendizajes en la formación de profesores de educación física: poniendo en juego la metacognición.

Elisondo et al. (2016). Estudiantes hoy, entre Facebook, Google y metacognición. Ideas para innovar en la Educación Superior. Revista de Docencia Universitaria, REDU, 14(1), 225-244. Recuperado de https:// polipapers.upv.es/index.php/REDu/article/view/5800. DOI: https://doi. org/10.4995/redu.2016.5800.

Elisondo, R., de la Barrera, M. L., Rigo, D., Fagotti Kucharski, E., Kowszyk, D., Ricetti, A. y Siracusa, M. (2015). Cómo leen, escriben y aprenden los estudiantes de educación superior. Innovación y mixtura en una experiencia de investigación. Educación, Formación e Investigación, EFI. 1(2). Recuperado de http://ppct.caicyt.gov.ar/index.php/efi/article/view/7153.

García-Ravidá, L. (2017). Patrones de aprendizaje en universitarios latinoamericanos: dimensión cultural e implicaciones educativas (tesis doctoral). Universitat Autónoma de Barcelona.

González, M. y Difabio de Anglat, H. (2016). Enfoque transversal y longitudinal en el estudio de patrones de aprendizaje en alumnos universitarios de ingeniería. Actualidades Investigativas en Educación, 16(3), 1-20. Dol: https://doi.org/10.15517/aie.v16i3.26089.

Martínez Fernández, J. R. (2015). Patrones de aprendizaje e investigación científica en enfermería. Revista Venezolana de Enfermería, 2(1), 7-11.

Martínez-Fernández, J. R., García-Ravidá, L., González-Velázquez, L., Gutiérrez-Braojos, C., Poggioli, L., Ramírez-Otálvaro, P. y Telleria, M. B. (2009). ıs Inventory of learning styles (en español). Barcelona: Universitat Autònoma de Barcelona.

Martínez Fernández, J. R. y García Ravidá, L. (2012). Patrones de aprendizaje en estudiantes universitarios del Máster en Educación Secundaria: variables personales y contextuales relacionadas. Profesorado. Revista del Currículum y Formación del Profesorado, 16(1), 166-182.

Martínez-Fernández, J. R. y Vermunt, J. D. (2015). A cross-cultural analysis of the patterns of learning and academic performance of Spanish and Latin-American undergraduates. Studies in Higher Education, 40(2), 278-295. 
Pérez Cabaní, M. L. (2000). El aprendizaje escolar desde el punto de vista del alumno: los enfoques de aprendizaje. En C. Coll, J. Palacios y A. Marchesi. Desarrollo psicológico y educación II (pp. 285-307). Madrid: Alianza.

Rodríguez Nouche, R., Bouza, G. y Alves De Lima, A. A. (2016). Estilos de aprendizaje y su rol en el desarrollo profesional continuo. Revista Argentina de Educación Médica, 7(1), 8-13.

Vázquez, S. M. (2009). Rendimiento académico y patrones de aprendizaje en estudiantes de ingeniería. Ing. Univ., 13(1), 105-136. Recuperado de http://www.javeriana.edu.co/Facultades/ingenieria/revista/Vol13nr1Aprendizaje.pdf.

Vermunt, J. (1998). The regulation of constructive learning processes. British Journal of Educational Psychology, 68, 149-171.

Vermunt, J. (2005). Relations between student learning patterns and personal and contextual factors and academic performance. Higher Education, 49, 205-234.

Vermunt, J. D., Bronkhorst, L. H. y Martínez-Fernández, J. R. (2014). The dimensionality of student learning patterns in different cultures. En D. Gijbels, V. Donche, J. T. E. Richardson y J. D. Vermunt (eds.), Learning patterns in higher education: Dimensions and research perspectives (pp. 33-55). Nueva York: Routledge.

Vermunt, J. D. y Vermetten, J. Y. (2004). Patterns in student learning: Relationships between learning strategies, mental models of learning and learning orientations. Educational Psychology Review, 16(4), 359-384. 